\title{
Bee products prevent VEGF-induced angiogenesis in human umbilical vein endothelial cells
}

\author{
Hiroshi Izuta1 ${ }^{1}$ Masamitsu Shimazawa1, Kazuhiro Tsuruma1 ${ }^{1}$ Yoko Araki ${ }^{2}$, \\ Satoshi Mishima ${ }^{2}$ and Hideaki Hara*1
}

Address: ${ }^{1}$ Department of Biofunctional Evaluation, Molecular Pharmacology, Gifu Pharmaceutical University, 5-6-1 Mitahora-higashi, Gifu 5028585, Japan and 2Nagaragawa Research Center, Api Co. Ltd., 692-3 Nagara, Gifu 502-0071, Japan

Email: Hiroshi Izuta - hizuta@hotmail.com; Masamitsu Shimazawa - shimazawa@gifu-pu.ac.jp; Kazuhiro Tsuruma - tsuruma@gifu-pu.ac.jp; Yoko Araki - araki-yoko@api3838.co.jp; Satoshi Mishima - mishima-satoshi@api3838.co.jp; Hideaki Hara* - hidehara@gifu-pu.ac.jp

* Corresponding author

Published: 17 November 2009

BMC Complementary and Alternative Medicine 2009, 9:45 doi:10.1 186/1472-6882-9-45

This article is available from: http://www.biomedcentral.com/1472-6882/9/45

(c) 2009 Izuta et al; licensee BioMed Central Ltd.

This is an Open Access article distributed under the terms of the Creative Commons Attribution License (http://creativecommons.org/licenses/by/2.0), which permits unrestricted use, distribution, and reproduction in any medium, provided the original work is properly cited.
Received: 9 September 2009
Accepted: 17 November 2009

\begin{abstract}
Background: Vascular endothelial growth factor (VEGF) is a key regulator of pathogenic angiogenesis in diseases such as cancer and diabetic retinopathy. Bee products [royal jelly (RJ), bee pollen, and Chinese red propolis] from the honeybee, Apis mellifera, have been used as traditional health foods for centuries. The aim of this study was to investigate the anti-angiogenic effects of bee products using human umbilical vein endothelial cells (HUVECs).

Methods: In an in vitro tube formation assay, HUVECs and fibroblast cells were incubated for 14 days with VEGF and various concentrations of bee products [R], ethanol extract of bee pollen, ethanol extract of Chinese red propolis and its constituent, caffeic acid phenethyl ester (CAPE)]. To clarify the mechanism of in vitro angiogenesis, HUVEC proliferation and migration were induced by VEGF with or without various concentrations of RJ, bee pollen, Chinese red propolis, and CAPE.

Results: RJ, bee pollen, Chinese red propolis, and CAPE significantly suppressed VEGF-induced in vitro tube formation in the descending order: CAPE > Chinese red propolis $>>$ bee pollen $>$ RJ. RJ and Chinese red propolis suppressed both VEGF-induced HUVEC proliferation and migration. In contrast, bee pollen and CAPE suppressed only the proliferation.
\end{abstract}

Conclusion: Among the bee products, Chinese red propolis and CAPE in particular showed strong suppressive effects against VEGF-induced angiogenesis. These findings indicate that Chinese red propolis and CAPE may have potential as preventive and therapeutic agents against angiogenesis-related human diseases.

\section{Background}

Angiogenesis, the formation of new vessels from pre-existing endothelium, is an important process in the adult organism because it supports the increasing demands for metabolic supplies (nutrients, various growth factors, and molecular oxygen) at sites of tissue repair or regeneration, during processes such as pregnancy, the female reproductive cycle, wound healing, and revascularization of ischemic tissues. However, excessive angiogenesis (neovascularization) is also characteristic of a number of serious diseases, including cancer, rheumatoid arthritis, retinal neovascularization, and atherosclerosis. The proc- 
ess of capillary sprouting in any of these normal or abnormal developments is likely to involve a multitude of regulatory molecules that mediate the distinct steps of extracellular matrix remodeling, endothelial cell migration, proliferation, lumen formation, and blood vessel maturation. These angiogenic events are regulated by a wide variety of growth factors including VEGF, basic fibroblast growth factor, and hepatocyte growth factor.

Royal jelly (RJ) from the honey bee, Apis mellifera, is a popular traditional health food all over the world. Chemical compositional analysis has shown that RJ consists mainly of proteins, sugars, fatty acids including 10hydroxy-2-decenoic acid (10 HDA), vitamins, and free amino acids [1]. RJ has several pharmacological functions including vasodilative activity [2], hypotensive activity [2], anti-tumor activity [3], and anti-hypercholesterolemic effects [4] among others.

Bee pollen is collected by honeybees as part of the nutrient harvest for the hive. Pollen contains carbohydrates, fatty acids, vitamins, minerals, and proteins, and is especially rich in free amino acids [5]. In traditional medicine, bee pollen is thought to be effective in prostatic conditions due to its presumed anti-inflammatory and antiandrogenic effects $[6,7]$.

Propolis is the resinous substance collected by bees from the leaf buds and bark of trees. Chemical analysis using gas chromatography-mass spectrometry has demonstrated that approximately 150 polyphenolic compounds, including flavonoids and cinnamic acid derivatives, are present in propolis [8]. Propolis has been used in folk medicines in many regions of the world and has been reported to have various biological activities, such as antibacterial [9], anti-inflammatory [10], and anti-tumor effects [11]. Recently, Ahn et al. have reported that Brazilian propolis and its constituents suppress tumor-induced angiogenesis through inhibition of tube formation [12].

CAPE, a phenolic antioxidant, is included in propolis. CAPE has many biological and pharmacological effects, including anti-inflammatory [13], anti-viral [14], and anti-tumor activities [15]. CAPE is a potent and specific inhibitor of activation of the nuclear transcription factor (NF-kB) [16]. In angiogenesis, CAPE has been shown to prevent VEGF expression in CT26 colon adenocarcinoma cells [17]. CAPE also suppresses the induction of prostaglandin E 2 synthesis [18] mediated by 12-O-tetradecanoylphorbol-13-acetate and calcium ionophores. Therefore, CAPE may be a potential anti-angiogenic agent that can reduce neovascularization.

The angiostatic effects of bee products, (RJ, bee pollen, and Chinese red propolis) have not yet been extensively examined. The purpose of the present study was to investigate the effects of bee products in the control of angiogenesis. We examined the effects of RJ, bee pollen, Chinese red propolis, and CAPE against VEGF-induced tube formation, proliferation, and migration, using human umbilical vein endothelial cells (HUVECs) as a model in vitro system.

\section{Methods \\ Materials}

HUVECs, endothelial cell basal medium (HuMedia-EB2), human epidermal growth factor (hEGF), human fibroblast growth factor B (hFGF B), hydrocortisone, heparin, VEGF, amphotericin B, and gentamicin were purchased from Kurabo (Osaka, Japan). Fetal bovine serum (FBS) was purchased from HyClone Laboratories (South Logan, UT). Collagen type I (Cellmatrix type I-C) was purchased from Nitta Gelatin Inc. (Osaka, Japan). GM6001 was purchased from SIGMA-Aldrich (St. Louis, MO, USA). RJ, 10 HDA, bee pollen, Chinese red propolis, and CAPE were gifted by Api Co. Ltd. (Gifu, Japan). Ruboxistaurin was gifted from Sanwa Kagaku Kenkyusho Co., Ltd.

\section{Bee products}

The RJ, produced by Apis mellifera, of Chinese origin, was a freeze-dried product. The bee pollen used in the present study originated from Jara pringosa (Cistus ladanifer L.) and Jara blanca (Cistus albidus L.) shrubs in Spain, and was extracted with 95\% ethanol at room temperature for $24 \mathrm{~h}$, and then filtrated to obtain the ethanol extract. The propolis used in this study was Chinese red propolis from Shandong, China, and was also extracted with 95\% ethanol at room temperature for $24 \mathrm{~h}$, and then filtered to obtain its ethanolic extract. RJ, bee pollen, Chinese red propolis, and CAPE were dissolved in dimethylsulfoxide (DMSO). DMSO, at the final concentration reached in each examination $(0.1 \%)$, was added to each bee product, the non-drug control, and VEGF alone.

\section{HPLC analysis}

The main constituents in ethanol extracts of Chinese red propolis were analyzed by high performance liquid chromatography (HPLC), the samples being injected into an HPLC system (Waters, Washington, NJ, USA) fitted with a Shim-pack CLC-ODS (Shimazu, Kyoto, Japan) C18 column $(\phi 6.0 \times 150 \mathrm{~mm})$. The mobile phase consisted of $1 \%$ acetic acid in 55\% methanol. All constituents of Chinese red propolis were measured at a wavelength of $290 \mathrm{~nm}$. Inject samples into HPLC system fitted with an Inertsil ODS-3 $(\phi 4.0 \times 150 \mathrm{~mm})$. The mobile phase consisted of $10 \mathrm{mM}$ PBS in methanol. The constituent was measured at a wavelength of $210 \mathrm{~nm}$. 


\section{Cell culture}

HUVECs were cultured in growth medium (HuMediaEG2) at $37^{\circ} \mathrm{C}$ in a humidified atmosphere of $5 \% \mathrm{CO}_{2}$ in air. The HuMedia-EG2 consists of basal medium (HuMedia-EB2) supplemented with $2 \%$ FBS, $10 \mathrm{ng} / \mathrm{ml}$ hEGF, 5 $\mathrm{ng} / \mathrm{ml} \mathrm{hFGF} \mathrm{B}, 1 \mu \mathrm{g} / \mathrm{ml}$ hydrocortisone, $10 \mu \mathrm{g} / \mathrm{ml}$ heparin, $50 \mathrm{ng} / \mathrm{ml}$ amphotericin $\mathrm{B}$, and $50 \mu \mathrm{g} / \mathrm{ml}$ gentamicin. Subconfluent monolayers of HUVECs, from passages 3 to 8, were used in the experiments.

\section{In vitro tube formation assay}

An angiogenesis assay kit (Kurabo) was used according to the manufacturer's instructions. This kit consists of a 24well cluster dish in which HUVECs and fibroblasts have been seeded in the optimal condition for capillary tube formation. The optimized angiogenesis medium in each well was changed on days $1,4,7$, and 9 with fresh medium containing VEGF $(10 \mathrm{ng} / \mathrm{ml})$ plus various concentrations of RJ (30 to $300 \mu \mathrm{g} / \mathrm{ml})$, GM6001 $(10 \mu \mathrm{M})$, bee pollen (30 to $300 \mu \mathrm{g} / \mathrm{ml}$ ), Chinese red propolis $(0.3$ to $3 \mu \mathrm{g} / \mathrm{ml})$, or CAPE $(1$ to $10 \mu \mathrm{M})$. Bee products and CAPE were dissolved in DMSO and diluted with culture medium. DMSO, at the final concentration reached in each examination $(0.1 \%)$, was added to the non-drug control, and samples containing VEGF alone.

On day 11, cells were fixed in $70 \%$ ethanol and stained with anti-CD31 antibody. For the evaluation of capillary tube formation (the stained tube-like structures), 100 $\mathrm{mm}^{2}$ areas of each well were photographed using a CCD camera (HS all-in-one fluorescence microscope; Keyence, Osaka, Japan). These photographs were then used for measurement of the tube area (the total area of the tubes), tube length (the total length of the tubes), joints (the number of capillary connections), and paths (the number of tubes branching from the capillary-like network) of the stained tube-like structures, using angiogenesis image analyzer version 2 (Kurabo).

\section{In vitro cell proliferation assay}

Subconfluent ( $\sim 80 \%)$ HUVECs were trypsinized, seeded into a 96-well plate at 2000 cells/well, and incubated in HuMedia-EG2 for $24 \mathrm{~h}$. The culture medium was then changed to HuMedia-EB2 with 2\% FBS, and incubation allowed to proceed for $24 \mathrm{~h}$. Fresh medium containing VEGF $(10 \mathrm{ng} / \mathrm{ml})$ was then added with or without various concentrations of RJ (100 to $300 \mu \mathrm{g} / \mathrm{ml}$ ), bee pollen (30 to $300 \mu \mathrm{g} / \mathrm{ml})$, Chinese red propolis $(0.3$ to $3 \mu \mathrm{g} / \mathrm{ml})$, CAPE ( 1 to $10 \mu \mathrm{M})$, or ruboxistaurin $(1 \mu \mathrm{M})$ and the incubation was continued for a further $72 \mathrm{~h}$. Cell proliferation was estimated by measuring cell metabolic activity using a Cell Counting Kit-8 (Dojindo, Kumamoto, Japan) according to the manufacturer's instructions. The viable cell numbers were measured using a water-soluble tetrazolium salt, 2-(2-methoxy-4-nitrophenyl)-3-(4-nitrophe-
nyl)-5-(2,4-disulfophenyl)-2H-tetrazolium (WST-8) and 1-methoxy-phenazine methosulfate. At the end of the drug treatments, the medium was replaced, then $10 \mu \mathrm{l}$ of WST-8 assay solution was added to each well, and incubation allowed to proceed for $3 \mathrm{~h}$ at $37^{\circ} \mathrm{C}$. Finally, the absorbance of the culture medium at $450 \mathrm{~nm}$ was measured using a microplate reader (Varioskan Flash, Thermo Electron Corporation, Vantaa, Finland).

\section{In vitro wounding-healing assay}

An in vitro wound-healing assay was performed to measure unidirectional migration by HUVECs. For this, we partially modified the procedure described by Izuta et al. (2007) [19]. Briefly, HUVECs $\left(4 \times 10^{4} /\right.$ well) were seeded in 12-well plates coated with collagen type I, and incubated at $37^{\circ} \mathrm{C}$ until they attached. The HUVECs were then washed twice with PBS and incubated in Humedia-EB2 with $1 \%$ FBS for $24 \mathrm{~h}$ at $37^{\circ} \mathrm{C}$. The monolayers of HUVECs were scratch-wounded to a $1 \mathrm{~mm}$ depth in a straight line using a 10-200 $\mu$ pipette-tip, and incubated with VEGF $(10 \mathrm{ng} / \mathrm{ml})$, with or without various concentrations of RJ (100 to $300 \mu \mathrm{g} / \mathrm{ml}), \mathrm{GM} 6001(10 \mu \mathrm{M})$, bee pollen (100 to $300 \mu \mathrm{g} / \mathrm{ml}$ ), Chinese red propolis (1 to 3 $\mu \mathrm{g} / \mathrm{ml}$ ), or CAPE (3 to $10 \mu \mathrm{M}$ ) for $24 \mathrm{~h}$. To measure the number of endothelial cells that had migrated from the edge of the injured monolayer, images were photographed both immediately after wounding and after $24 \mathrm{~h}$ incubation, using a phase-contrast microscope (OLYMPUS, Tokyo, Japan). At least four points in each of three fields were examined at random for two independent wounds.

\section{Statistical analysis}

Data are given as mean \pm SEM. Statistical analysis was performed using a Dunnett's multiple-comparison test, with $P<0.05$ being considered to indicate statistical significance.

\section{Results}

\section{Bee products and their constituents}

Firstly, we analyzed the content of major constituents included in RJ and Chinese red propolis. 10 HDA, a unique medium chain fatty acid, was contained $5.8 \%$ in RJ (Table 1). On the other hand, Chinese red propolis contains following constituents (caffeic acid, 1.3\%; $p$-coumaric acid, 4.0\%; caffeic acid phenethyl ester, $1.7 \%$; chrysin, 5.0\%; galangin, $3.7 \%$; pinocembrin, $8.4 \%$ ) (Table 1 ).

\section{In vitro tube formation}

New capillary formation is required for the initial steps of angiogenesis, which involves processes such as endothelial cell activation, proliferation, and migration. To investigate the inhibitory effects of bee products, we evaluated the effects of RJ, bee pollen, Chinese red propolis, and CAPE on VEGF-induced tube formation in HUVECs. 
Table I: Main component's contents in royal jelly $(R J)$ extract and ethanol extracts of Chinese red propolis

\begin{tabular}{lc}
\hline $\begin{array}{l}\text { Royal jelly } \\
\text { - I0-hydroxy-2-decenoic acid }\end{array}$ & $\begin{array}{c}\text { Content (\%) } \\
5.8\end{array}$ \\
\hline Chinese red propolis & Content (\%) \\
- Caffeic acid & 1.3 \\
- $\rho$-Coumaric acid & 4.0 \\
- Caffeic acid phenethyl ester & 1.7 \\
- Chrysin & 5.0 \\
- Galangin & 3.7 \\
- Pinocembrin & 8.4
\end{tabular}

The values represent contents of each component (\%) included in RJ and Chinese red propolis.

VEGF stimulated the formation of capillary-like structures by HUVECs, and this action was significantly suppressed by addition of RJ, bee pollen, Chinese red propolis, and CAPE (Figure 1). To evaluate tube formation by endothelial cells in a quantitative manner, tube area, tube length, joints, and paths were measured using an imaging analyzer. RJ, bee pollen, Chinese red propolis, and CAPE suppressed the tube area following VEGF-induced tube formation. In addition, GM6001, a matrix metalloproteinase inhibitor, suppressed the tube formation. Statistically significant effects were seen for concentrations of RJ (100 to $300 \mu \mathrm{g} / \mathrm{ml}$ ), GM6001 $(10 \mu \mathrm{M})$, bee pollen (30 to
$300 \mu \mathrm{g} / \mathrm{ml}$ ), Chinese red propolis ( 0.3 to $3 \mu \mathrm{g} / \mathrm{ml}$ ), and CAPE ( 1 to $10 \mu \mathrm{M}$ ) (Figure 2). These compounds also suppressed the other parameters of tube formation (tube length, joints, and paths) in a concentration-dependent manner (Figure 2).

\section{Cell proliferation}

For a specific evaluation of vascular endothelial cell proliferation, a key initial step in angiogenesis, we examined whether RJ, bee pollen, Chinese red propolis, and CAPE might inhibit VEGF-induced HUVEC proliferation. In the VEGF alone group, the proliferation of HUVEC was increased 1.8-2.2 fold (vs. control). RJ, Chinese red propolis, and CAPE potently suppressed this VEGF-induced HUVEC proliferation, with effects being significant at concentrations of $300 \mu \mathrm{g} / \mathrm{ml}, 3 \mu \mathrm{g} / \mathrm{ml}$, and 3-10 $\mu \mathrm{M}$, respectively (Figure 3A, C, and 3D). On the other hand, bee pollen only weakly, but significantly, suppressed the proliferation at a concentration of $300 \mu \mathrm{g} / \mathrm{ml}$ (Figure 3B). In addition, ruboxistaurin, a PKC beta inhibitor, also suppressed the proliferation (Figure $3 \mathrm{~A}$ ).

\section{Cell migration}

For a further investigation of the anti-angiogenic effects, we tested the effects on vascular endothelial cell migration, an essential step in angiogenesis. We employed a wound-healing assay using HUVECs. Briefly, after starva-
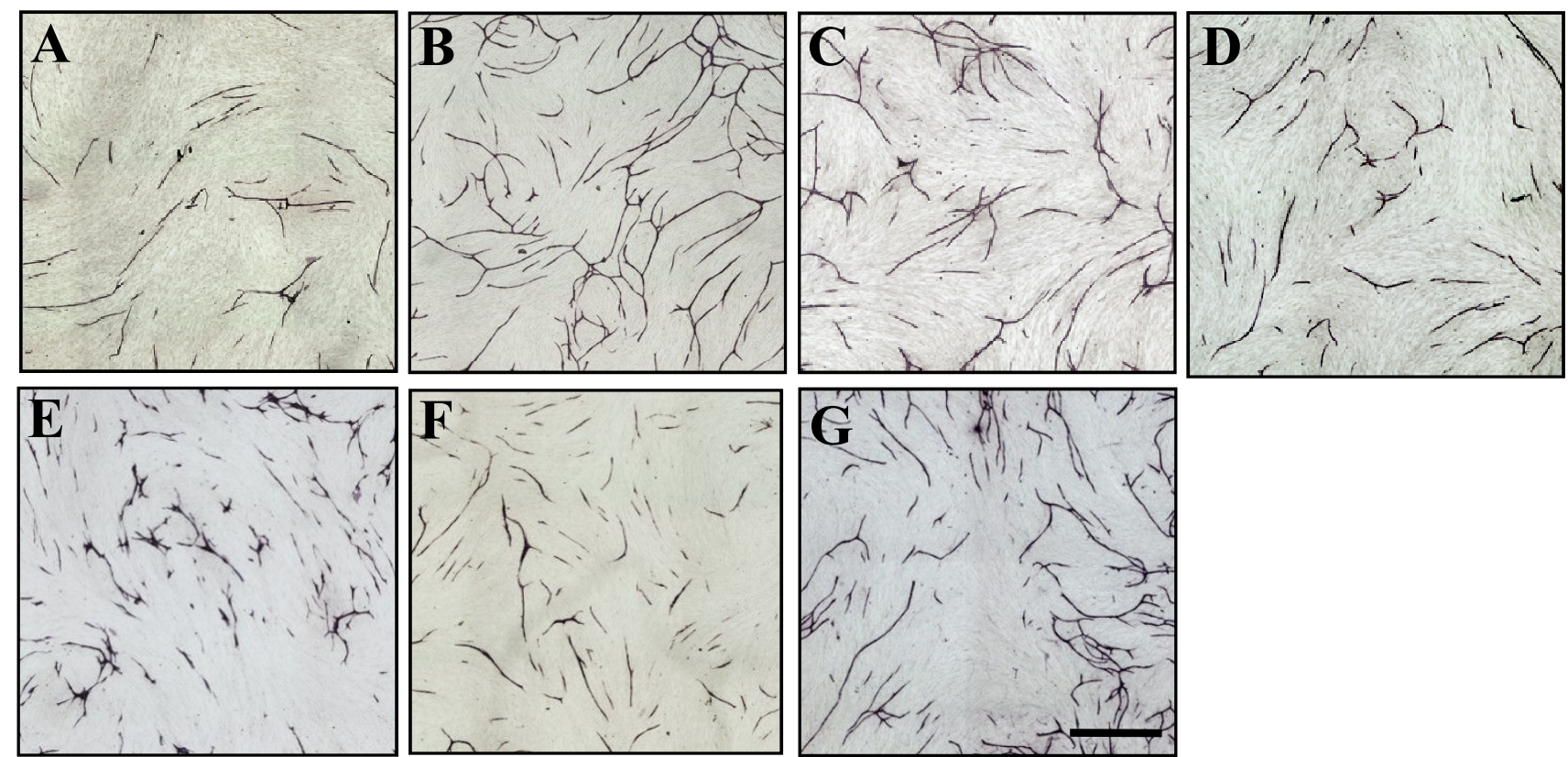

Figure I

Representative photographs of the effects of bee products on in vitro tube formation in HUVECs. A) Control, B) VEGF alone, and VEGF plus C) royal jelly $(300 \mu \mathrm{g} / \mathrm{ml})$, D) bee pollen ( $100 \mu \mathrm{g} / \mathrm{ml})$, E) Chinese red propolis (I.0 $\mu \mathrm{g} / \mathrm{ml})$, and F) caffeic acid phenethyl ester (CAPE: $3 \mu \mathrm{M}), \mathrm{G}) \mathrm{GM600I}$ (I0 $\mu \mathrm{M}$ ) after staining with CD-3I antibody. Scale bar represents I mm. 


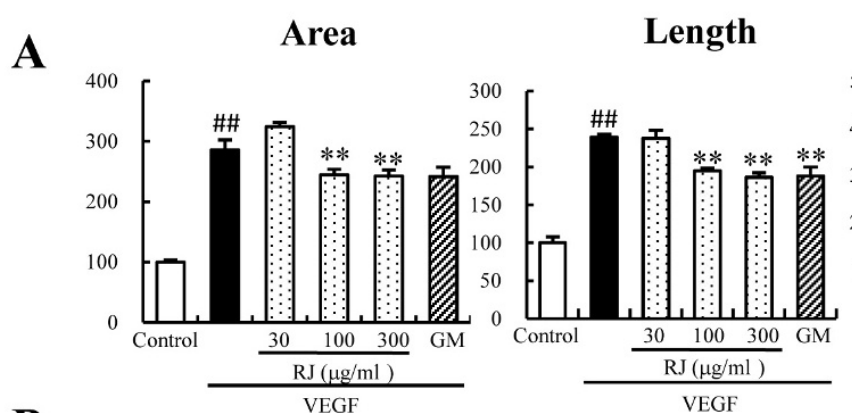

Joints

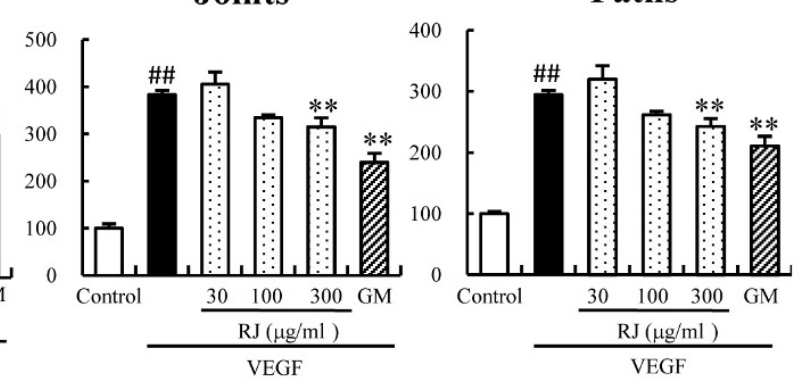

B

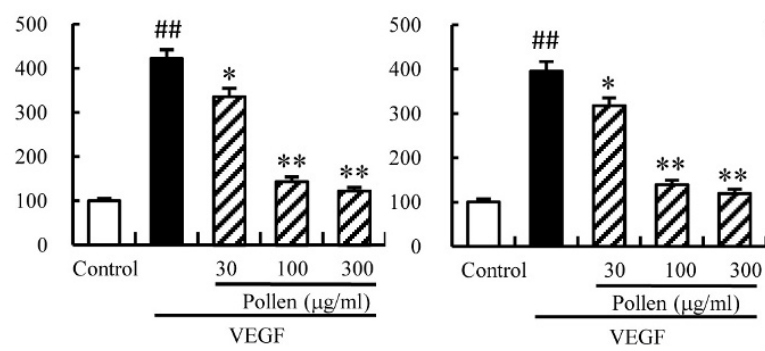

C


D


Figure 2

The effects of bee products on in vitro tube formation in HUVECs. A-D) Tube formation was evaluated by measurements of tube area, tube length, joints, and paths after treatment with A) royal jelly (RJ) and GM600I, B) bee pollen, C) Chinese red propolis, and D) caffeic acid phenethyl ester (CAPE), as described in "Methods". GM represents GM600I, a matrix metalloproteinase inhibitor. Data represent means \pm SEM $(n=3)$. \#\#: $P<0.01$ vs. Control, $*: P<0.05, * *: P<0.01$ vs. VEGF alone.

tion, confluent scrape-wounded HUVEC monolayers were incubated with VEGF $(10 \mathrm{ng} / \mathrm{ml})$ in the presence or absence of RJ, bee pollen, Chinese red propolis, CAPE, or GM6001, and the number of cells that had migrated into the wound region was assessed $24 \mathrm{~h}$ later (Figure 4A). In the VEGF alone group, the number of migrating cells was increased 1.8-2.5 fold (vs. the control group). RJ (300 $\mu \mathrm{g} /$ $\mathrm{ml}$ ) and Chinese red propolis ( $3 \mu \mathrm{g} / \mathrm{ml})$ significantly suppressed the VEGF-induced HUVEC migration, however bee pollen (100 to $300 \mu \mathrm{g} / \mathrm{ml}$ ) or CAPE (3 to $10 \mu \mathrm{M}$ ) had no effect on the migration (Figure 4B-E). In addition, GM6001 $(10 \mu \mathrm{M})$ also suppressed the migration (Figure $4 B)$. 

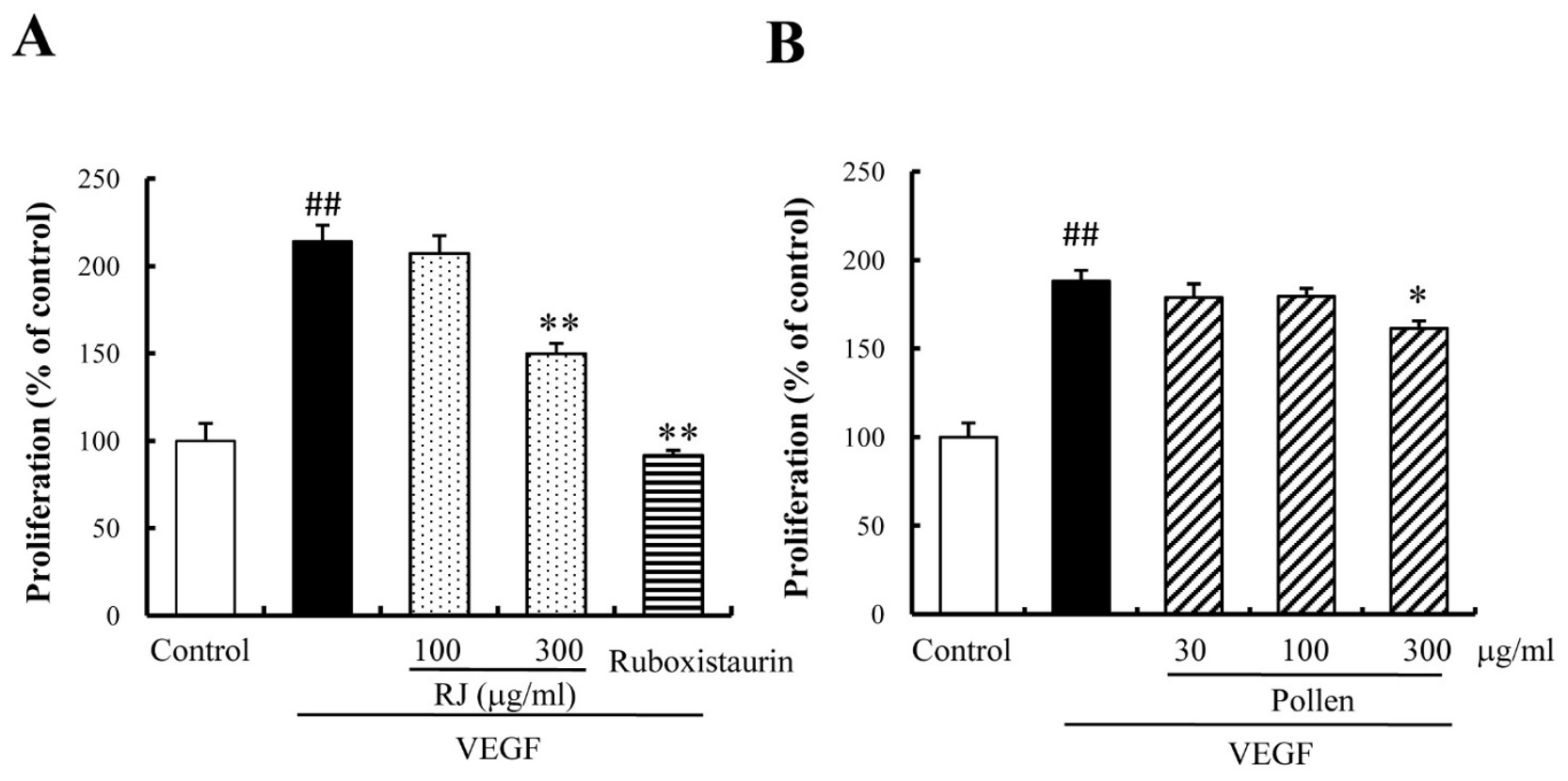

C

\section{D}


Figure 3

The effects of bee products on VEGF-induced proliferation in HUVECs. HUVECs were incubated with the indicated concentrations of $(A)$ royal jelly $(R J)$ and ruboxistaurin, $(B)$ bee pollen, $(C)$ Chinese red propolis, and (D) caffeic acid phenethyl ester (CAPE) in the presence or absence of VEGF $(10 \mathrm{ng} / \mathrm{ml})$ for 3 days at $37^{\circ} \mathrm{C}$ in $5 \% \mathrm{CO}_{2}$ with humidity. Cell proliferation was estimated using a cell counting kit-8 (CCK-8). VEGF treatments increased cell viability two-fold (vs. Control). RJ (300 $\mu$ g/ $\mathrm{ml})$, ruboxistaurin $(\mathrm{I} \mu \mathrm{M})$, bee pollen $(300 \mu \mathrm{g} / \mathrm{ml})$, Chinese red propolis $(3 \mu \mathrm{g} / \mathrm{ml})$, and CAPE $(3$ to $10 \mu \mathrm{M})$ inhibited the proliferation. Data represent means $\pm \operatorname{SEM}(n=6)$. \#\#: $P<0.01$ vs. Control, $*: P<0.05, * *: P<0.01$ vs. VEGF alone.

\section{Discussion}

In this study, we clarified that RJ, bee pollen, Chinese red propolis, and CAPE suppressed VEGF-induced tube formation in HUVECs. The suppressive effects of Chinese red propolis and CAPE were stronger than those of RJ and bee pollen. RJ and Chinese red propolis suppressed VEGFinduced proliferation and migration in HUVECs, whereas bee pollen and CAPE suppressed only the proliferation. This is the first report of angiostatic effects of RJ and bee pollen extracts in HUVECs. 




B

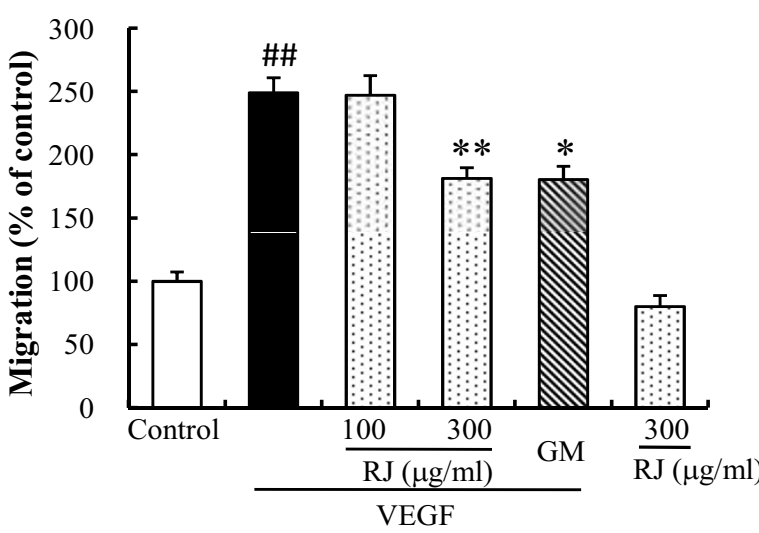

C

$\mathbf{D}$


$\mathbf{E}$

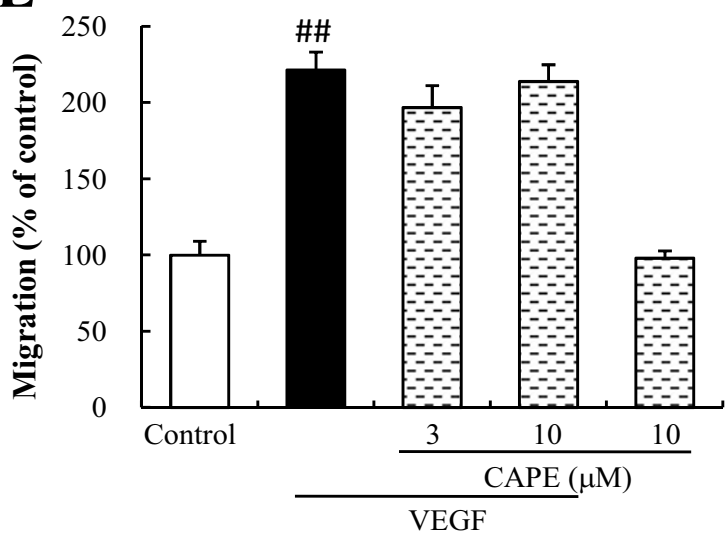

Figure 4

The effects of bee products on VEGF-induced migration and in vitro wound healing. A) Images of wounded monolayers of HUVEC taken at $24 \mathrm{~h}$ after treatment with control, VEGF alone $(10 \mathrm{ng} / \mathrm{ml})$, VEGF plus royal jelly (RJ) $(300 \mu \mathrm{g} / \mathrm{ml})$, VEGF plus bee pollen $(300 \mu \mathrm{g} / \mathrm{ml})$, VEGF plus Chinese red propolis $(3 \mu \mathrm{g} / \mathrm{ml})$, or VEGF plus caffeic acid phenethyl ester (CAPE) $(10 \mu \mathrm{M})$. Scale bar represents $250 \mu \mathrm{m}$. Migration was estimated by measuring the cell numbers within the wounded region after treatment with VEGF (I0 ng/ml) with or without (B) RJ (I00 to $300 \mu \mathrm{g} / \mathrm{ml})$ and GM600I (I0 $\mu$ M), (C) bee pollen (I00 or $300 \mu \mathrm{g} / \mathrm{ml}$ ), (D) Chinese red propolis (I to $3 \mu \mathrm{g} / \mathrm{ml})$, or (E) CAPE (3 or $10 \mu \mathrm{M})$. GM represents GM600I, a matrix metalloproteinase inhibitor. Data represent means $\pm \operatorname{SEM}(n=4)$. \#: $P<0.01$ vs. Control, $* *: P<0.01$ vs. VEGF alone. 
ROS production promotes angiogenesis and typical antioxidant, N-acetylcysteine suppresses VEGF-induced tube formation [20]. Therefore, ROS may play a pivotal role against VEGF-induced angiogenesis. Previously, we compared the antioxidant activities of bee products and their constituents using 1,1-diphenyl-2-picrylhydrazyl (DPPH) radical scavenging activity, and found that Chinese red propolis and CAPE exhibit strong antioxidant activities among bee products, and the $\mathrm{IC}_{50}$ values were 18.5 and $3.6 \mu \mathrm{g} / \mathrm{ml}(12.8 \mu \mathrm{M})$, whose values respectively [21]. Bee pollen extract exhibited relatively weak antioxidant activities, and the $\mathrm{IC}_{50}$ value was $196.7 \mu \mathrm{g} / \mathrm{ml}$ (Table 2) [21]. On the other hand, angiostatic activities of bee products (CAPE, Chinese red propolis, bee pollen, and RJ) exhibited $0.3 \mu \mathrm{g} / \mathrm{ml}(1 \mu \mathrm{M}), 3,100$, and $300 \mu \mathrm{g} / \mathrm{ml}$, whose values represented minimum concentrations suppressing all four parameters (tube area, tube length, joint, and path) in an in vitro tube formation assay. The antioxidant activities of each bee product were well corresponding with their angiostatic activities in an in vitro tube formation. The higher order of antioxidant activities among bee products were CAPE $>$ Chinese red propolis $>>$ bee pollen. On the other hand, the higher order of angiostatic activities were also CAPE > Chinese red propolis $>>$ bee pollen. These results suggest that angiostatic effects of bee products may be partly dependent on their antioxidant activities, except for RJ.

Previously, we were able to show angiostatic effect of 10 HDA, a constituent of RJ, against VEGF-induced tube formation, at concentrations of $20 \mu \mathrm{M}$ or more [19]. In the present study, RJ suppressed VEGF-induced tube formation at concentrations of $100 \mu \mathrm{g} / \mathrm{ml}$ or more (Figure $2 \mathrm{~A}$ ). Dried RJ used in the present study contains $10 \mathrm{HDA}$ at $5.8 \%$ (Table 1). From this composition, $10 \mathrm{HDA}$ at 31.1 $\mu \mathrm{M}$ is included in RJ at a concentration of $100 \mu \mathrm{g} / \mathrm{ml}$. These results indicate that the angiostatic effects of RJ may be mainly dependent on 10 HDA.

In the present study, Chinese red propolis and its constituent, CAPE, suppressed VEGF-induced angiogenesis in HUVECs (Figure 2). The minimum concentration of CAPE against VEGF-induced tube formation was 10 times lower than that of Chinese red propolis (Table 2). How- ever, the CAPE content in the propolis was only $1.7 \%$ (Table 1), suggesting that other constituents in the propolis may influence the inhibitory effects. Previous report indicates that pinocembrin and galangin suppress tube formation in HUVECs [22], and in this study, we confirmed that these flavonoids (pinocembrin and galangin) were included in Chinese red propolis $(8.4 \%$ and $3.7 \%$, respectively). Therefore, these results indicate that not only CAPE but also other flavonoids (pinocembrin and galangin) are important components for angiostatic effect of Chiese red propolis.

In the present study, we investigated the effects of bee products on VEGF-induced cell proliferation and migration, in order to clarify the mechanism suppressing in vitro tube formation. RJ and Chinese red propolis inhibited VEGF-induced tube formation in a concentrationdependent manner via suppression of cell proliferation and migration of the HUVECs (Figs. 2, 3, and 4). On the other hand, CAPE inhibited the tube formation via a strong suppression of HUVEC proliferation (Figs. 2 and 3). Although bee pollen strongly inhibited in vitro tube formation, it exhibited only a weakly suppressive effect on cell proliferation and did not affect the migration of HUVECs (Figs. 2, 3, and 4).

In this study, to clarify the angiostatic mechanism of bee products, we examined only cell proliferation and migration assays. However, new capillary formation also involves various angiogenic processes, such as endothelial cell activation, alignment, anastomosis, and maturation of intercellular junctions. Hence, bee pollen may have a specific inhibitory mechanism on these angiogenic processes rather than on processes that regulate cell proliferation and migration.

In a previous study, we found that Brazilian green propolis and its constituent caffeoylquinic acid derivatives suppressed VEGF-induced cell proliferation, migration, and in vitro tube formation in HUVECs [23]. In the present study, Chinese red propolis and its chemical constituent, CAPE, suppressed VEGF-induced in vitro tube formation. Caffeic acid is a known suppressor of tumor angiogenesis that acts in human retinal carcinoma cells by blocking

Table 2: Correlation between antioxidant activities and angiostatic activities of bee products

\begin{tabular}{lrr}
\hline & Antioxidant activities $(\mu \mathbf{g} / \mathbf{m l})$ & Angiostatic activities $(\mu \mathbf{g} / \mathbf{m l})$ \\
\hline Caffeic acid phenethyl ester & 3.6 & 0.3 \\
Chinese red propolis & 18.5 & 3.0 \\
Bee pollen & 196.7 & 100.0 \\
Royal jelly & - & 300.0 \\
\hline
\end{tabular}

Antioxidant activities show the DPPH radical scavenging activities of bee products. These data represents the values of $I C_{50}$. Angiostatic activities are represented by the minimal concentrations at which each bee products suppresses all of parameters against VEGF-induced tube formation. Data of antioxidant activities in this table were partially modified from Izuta et al. [2I]. 
STAT3-mediated VEGF expression [24]. These studies indicate that caffeoyl groups included in propolis may be important components responsible for its anti-angiogenic activities.

The pharmacological effects of bee products have been reported in many different diseases. In particular, there are many reports about the anti-tumor effects of propolis and CAPE. Our previous studies indicate that baccharin and drupanin, constituents of Brazilian propolis, inhibit tumor growth both in vitro and in vivo [25]. Likewise, CAPE induces growth arrest and apoptosis of colon cancer cells via the beta-catenin/T-cell factor signaling pathway [26]. Tumor angiogenesis is a very important step in the growth and metastasis of tumor development. Combined with these findings in the present study, Chinese propolis and its CAPE constituent suppressed VEGF-induced angiogenesis in HUVECs indicates that the anti-tumor effects of propolis and CAPE may be dependent both on direct inhibition of tumor cell growth and on angiostatic effects on the vessels supplying nutrients to the neoplasm.

\section{Conclusion}

Combined with the findings in the present study that Chinese propolis and its CAPE constituent suppressed VEGFinduced angiogenesis in HUVECs, the angiostatic effects of Chinese red propolis and its CAPE constituent may have potential as therapeutic agents against proangiogenic diseases.

\section{Competing interests}

The authors declare that they have no competing interests.

\section{Authors' contributions}

HI, MS, KT, YA-Collection, analysis, and interpretation of the data; HH-Design of the study management; MS, SM, KT, YA, HH-Preparation, review, or approval of the manuscript. All authors read and approved the final manuscript.

\section{References}

I. Takenaka T: Chemical composition of royal jelly. Honeybee Science 1982, 3:69-74.

2. Shinoda M, Nakajin S, Oikawa T, Sato K, Kamogawa A, Akiyama Y: [Biochemical studies on vasodilative factor in royal jelly (author's transl)]. Yakugaku Zasshi 1978, 98(2): |39-| 45.

3. Tamura T, Fujii A, Kuboyama N: [Antitumor effects of royal jelly (RJ)]. Nippon Yakurigaku Zasshi 1987, 89(2):73-80.

4. Vittek J: Effect of royal jelly on serum lipids in experimental animals and humans with atherosclerosis. Experientia 1995. II (9-10):927-935.

5. Campos MG, Cunha A, Markham KR: IN Bee Products (Mizrahi and Lensky eds). Plenum Press, New York; 1996.

6. Buck AC, Rees RW, Ebeling L: Treatment of chronic prostatitis and prostatodynia with pollen extract. $\mathrm{Br} /$ Urol 1989, 64(5):496-499.

7. Buck AC, Cox R, Rees RW, Ebeling L, John A: Treatment of outflow tract obstruction due to benign prostatic hyperplasia with the pollen extract, cernilton. A double-blind, placebocontrolled study. Br J Urol 1990, 66(4):398-404.
8. Greenaway W, May J, Scaysbrook T, Whatley FR: Identification by gas chromatography-mass spectrometry of 150 compounds in propolis. Zeitschrift für Naturforschung C I991, 46: III-121.

9. Bankova V, Marcucci MC, Simova S, Nikolova N, Kujumgiev A, Popov S: Antibacterial diterpenic acids from Brazilian propolis. $Z$ Naturforsch [C] 1996, 5 I (5-6):277-280.

10. Mirzoeva OK, Calder PC: The effect of propolis and its components on eicosanoid production during the inflammatory response. Prostaglandins Leukot Essent Fatty Acids 1996, 55(6): $44 \mid-449$.

11. Chen CN, Weng MS, Wu CL, Lin JK: Comparison of Radical Scavenging Activity, Cytotoxic Effects and Apoptosis Induction in Human Melanoma Cells by Taiwanese Propolis from Different Sources. Evid Based Complement Alternat Med 2004, I(2): I75-I85.

12. Ahn MR, Kunimasa K, Ohta T, Kumazawa S, Kamihira M, Kaji K, Uto Y, Hori H, Nagasawa H, Nakayama T: Suppression of tumorinduced angiogenesis by Brazilian propolis: major component artepillin $C$ inhibits in vitro tube formation and endothelial cell proliferation. Cancer Lett 2007, 252(2):235-243.

13. Jung WK, Lee DY, Choi YH, Yea SS, Choi I, Park SG, Seo SK, Lee SW, Lee CM, Kim SK, et al:: Caffeic acid phenethyl ester attenuates allergic airway inflammation and hyperresponsiveness in murine model of ovalbumin-induced asthma. Life Sci 2008 , 82(I3-I 4):797-805.

14. Fesen MR, Kohn KW, Leteurtre F, Pommier Y: Inhibitors of human immunodeficiency virus integrase. Proc Natl Acad Sci USA 1993, 90(6):2399-2403

15. Orsolic N, Terzic S, Mihaljevic Z, Sver L, Basic I: Effects of local administration of propolis and its polyphenolic compounds on tumor formation and growth. Biol Pharm Bull 2005, 28(10): 1928-1933.

16. Natarajan K, Singh S, Burke TR Jr, Grunberger D, Aggarwal BB: Caffeic acid phenethyl ester is a potent and specific inhibitor of activation of nuclear transcription factor NF-kappa B. Proc Natl Acad Sci USA 1996, 93( 17 ):9090-9095.

17. Liao HF, Chen YY, Liu J], Hsu ML, Shieh HJ, Liao HJ, Shieh C], Shiao MS, Chen YJ: Inhibitory effect of caffeic acid phenethyl ester on angiogenesis, tumor invasion, and metastasis. I Agric Food Chem 2003, 5 I (27):7907-79/2.

18. Michaluart P, Masferrer JL, Carothers AM, Subbaramaiah K, Zweifel BS, Koboldt C, Mestre JR, Grunberger D, Sacks PG, Tanabe T, et al.: Inhibitory effects of caffeic acid phenethyl ester on the activity and expression of cyclooxygenase- 2 in human oral epithelial cells and in a rat model of inflammation. Cancer Res 1999, 59( (10):2347-2352

19. Izuta H, Chikaraishi Y, Shimazawa M, Mishima S, Hara H: 10 Hydroxy-2-decenoic Acid, a Major Fatty Acid from Royal Jelly, Inhibits VEGF-induced Angiogenesis in Human Umbilical Vein Endothelial Cells. Evid Based Complement Alternat Med 2007.

20. Ushio-Fukai M, Tang Y, Fukai T, Dikalov SI, Ma Y, Fujimoto M, Quinn MT, Pagano PJ, Johnson C, Alexander RW: Novel role of gp9l(phox)-containing $\mathrm{NAD}(\mathrm{P}) \mathrm{H}$ oxidase in vascular endothelial growth factor-induced signaling and angiogenesis. Circ Res 2002, 9 I (12): 1 160-1 I67.

21. Izuta H, Narahara Y, Shimazawa M, Mishima S, Kondo S, Hara H: I, IDiphenyl-2-Picrylhydrazyl (DPPH) Radical Scavenging Activity of Bee Products and Their Constituents Determined by ESR. Biol Pharm Bull 2009 in press.

22. Ahn MR, Kunimasa K, Kumazawa S, Nakayama T, Kaji K, Uto Y, Hori $\mathrm{H}$, Nagasawa $\mathrm{H}$, Ohta $\mathrm{T}$ : Correlation between antiangiogenic activity and antioxidant activity of various components from propolis. Mol Nutr Food Res 2009, 53(5):643-65I.

23. Chikaraishi Y, Izuta H, Shimazawa M, Mishima S, Hara H: Angiostatic effects of Brazilian green propolis and its chemical constituents. Molecular Nutrition \& Food Research 2009 in press.

24. Jung JE, Kim HS, Lee CS, Park DH, Kim YN, Lee MJ, Lee JW, Park JW, Kim MS, Ye SK, et al.: Caffeic acid and its synthetic derivative CADPE suppress tumor angiogenesis by blocking STAT3. mediated VEGF expression in human renal carcinoma cells. Carcinogenesis 2007, 28(8): 1780-1787.

25. Mishima S, Ono Y, Araki Y, Akao Y, Nozawa Y: Two related cinnamic Acid derivatives from Brazilian honey bee propolis, baccharin and drupanin, induce growth inhibition in allo- 
grafted sarcoma S-180 in mice. Biol Pharm Bull 2005, 28(6): $1025-1030$.

26. Xiang D, Wang D, He Y, Xie J, Zhong Z, Li Z, Xie J: Caffeic acid phenethyl ester induces growth arrest and apoptosis of colon cancer cells via the beta-catenin/T-cell factor signaling. Anticancer Drugs 2006, I7(7):753-762.

\section{Pre-publication history}

The pre-publication history for this paper can be accessed here:

http://www.biomedcentral.com/1472-6882/9/45/prepub

Publish with Bio Med Central and every scientist can read your work free of charge

"BioMed Central will be the most significant development for disseminating the results of biomedical research in our lifetime. " Sir Paul Nurse, Cancer Research UK

Your research papers will be:

- available free of charge to the entire biomedical community

- peer reviewed and published immediately upon acceptance

- cited in PubMed and archived on PubMed Central

- yours - you keep the copyright

Submit your manuscript here:

http://www.biomedcentral.com/info/publishing_adv.asp 